\title{
PENGEMBANGAN MEDIA PEMBELAJARAN PLDV TERHADAP KEMAMPUAN KEMANDIRIAN BELAJAR MATEMATIS PESERTA DIDIK SMP
}

\author{
Ade Lukman Nulhakim ${ }^{1}$, Arif Susanto ${ }^{2}$, Ahmad Husain ${ }^{3}$ \\ 1,2,3 Teknik Informatika, Fakultas Teknik dan Ilmu Komputer, Universitas Indraprasta PGRI \\ Jl. Nangka 58C Tanjung Barat, Jagakarsa, Jakarta Selatan \\ ${ }^{1}$ ade.lukman1330@gmail.com, ${ }^{2}$ arifsusanto14@gmail.com, ${ }^{3}$ hnr.husen@gmail.com
}

\begin{abstract}
ABSTRAK
Masih banyak nya peserta didik mengalami kesulitan membuat pemodelan matematika dan memahami konsep pemodelan di tingkat SMP membuat perlunya dikembangkan model pembelajaran yang dapat membantu dan membuat peserta didik memahami pola dan konsep untuk menyusun dan menyelesaiakannya. Materi PLDV merupakan salah satu materi dalam pembelajaran matematika yang menerapkan konsep pemodelan agar lebih mudah bagi peserta didik dalam menyelesaikan solusi nya. Materi PLDV dianggap sulit oleh peserta didik karena selain perlu menggabarkan permasalahannya ke dalam model matematika dengan menggunakan penyelesaian persamaan mereka juga perlu membuat pola penyelesaian dengan berbagai cara. Banyaknya peserta didik kesulitan bahkan salah dalam menggunakan aturan seperti pada konsep eliminasi dan substitusi. Dengan memanfaatkan kecanggihan teknologi, maka dikembangkan media pembelajaran untuk membantu pemahaman matematika peserta didik. Penelitian pengembangan media pembelajaran PLDV ini berlangsung di salah satu SMP Swasta di Jakarta. Metode dalam penelitian ini mengusung metode R\&D. Dari penelitian diketahui bahwa : (1) ahli pendidikan memberikan penilaian baik dengan rata-rata penilaian sebesar 72,86\% (2) ahli multimedia memberikan penilaian baik dengan rata-rata penilaian sebesar $72 \%$ (3) ahli matematika memberikan penilaian baik dengan rata-rata penilaian sebesar $75 \%$ (4) uji skala terbatas yang dilakukan memperoleh hasil akhir sebesar $81 \%$ berada pada kategori sangat baik.
\end{abstract}

Kata Kunci: Media Interaktif, PLDV, Pemodelan Matematika

\begin{abstract}
There are still many students who have difficulty making mathematical modeling and understanding modeling concepts at the junior high school level, making it necessary to develop learning models that can help and make students understand patterns and concepts to develop and solve them. PLDV material is one of the materials in mathematics learning that applies modeling concepts to make it easier for students to complete their solutions. The PLDV material is considered difficult by students because in addition to the need to describe the problem into a mathematical model using equation solving, they also need to create patterns of settlement in various ways. Many students find it difficult or even wrong to use rules such as the concepts of elimination and substitution. By utilizing technological sophistication, learning media are developed to help students understand mathematics. This research on the development of PLDV learning media took place in one of the private junior high schools in Jakarta. The method in this study carries the R\&D method. From the research it is known that: (1) education experts give a good assessment with an average rating of $72.86 \%$ (2) multimedia experts give a good assessment with an average rating of 72\% (3) mathematicians give a good assessment with an average an average rating of $75 \%$ (4) the limited scale test carried out obtained a final result of $81 \%$ in the very good category.
\end{abstract}

Key Word: Interactive Media, PLDV, Mathematical Modeling

\section{PENDAHULUAN}

Pendidikan memiliki peranan penting dalam membentuk kader suatu bangsa yang cerdas dan berintelektual. Untuk mencapai hal tersebut maka perlu upaya yang sungguhsungguh dari semua pihak baik yang terlibat langsung atau tidak langsung dalam dunia pendidikan itu sendiri. Guru selaku pemeran langsung memiliki andil besar terhadap kualitas pencapaian yang dialami peserta didiknya. Untuk itu guru selaku pengajar perlu memiliki cara jitu dan berbagai keahlian dalam membuat dan merancang model pembelajaran yang berorientasi pada aktivitas siswa agar proses kegiatan belajar mengajar di sekolah menjadi lebih berwarna.

Perancangan pembelajaran yang dimaksud adalah guru mampu membuat nuansa belajar yang berbeda atau menerapkan suasana 
belajar baru yang dapat meningkatkan peran peserta didik dalam keikutsertaannya terlibat sebagai peserta didik yang aktif. Guru mampu berperan sebagai sosok yang tidak terlalu dominan sebagai sosok pemberi pengetahuan, namun tetap menjadi sosok kunci yaitu seorang fasilitator yang bertugas untuk membimbing dan mengaktifkan peserta didik secara emosional, spiritual, intelektual, mental dan aktifivitasnya. Dengan menitik beratkan pembelajaran yang terpusat pada peserta didik. Diharapkan tujuan pembelajaran akan tercapai.

Dalam kegiatan belajar mengajar guru perlu menyadari posisi nya sebagai fasilitator dan peserta didik sebagai subjek pebelajar. Hal ini sesuai dengan pendapat Raka Joni ( Pardjono, 2000) mengenai prinsip yang kedua berkaitan dengan peranan guru di dalam kelas, yaitu mengikuti prinsip "tut wuri handayani", di mana guru berperan sebagai fasilitator dalam belajar, dengan mendorong, membimbing, memberi model tanpa bermaksud untuk mendominasi kegiatan di kelas. Dalam hal ini peran guru berubah dari pemberi pengetahuan menjadi fasilitator bagi terjadinya proses konstruksi pengetahuan anak. Jika dalam kegiatan pembelajaran peserta didik di posikan sebagai subjek pebelajar, maka dengan demikian kegiatan belajar mengajar akan berpusat kepada peserta didik sebagai pusat perhatian, maka kegiatan belajar mengajar akan semakin bermakna. Oleh karena itu strategi pembelajaran matematika harus diorientasikan kepada peserta didik, sehingga interaksi yang terjadi dalam proses belajar mengajar dapat berjalan sesuai dengan yang diharapkan, karena pola pengajaran yang berpusat pada peserta didik. Hal ini sesuai dengan hasil penelitian Rahman et al.(Abdullah \& Suratno, 2015) menunjukkan bahwa pembelajaran aktif mendorong siswa untuk belajar secara mandiri adalah strategi pembelajaran yang dapat mengembangkan kemampuan komunikasi matematis siswa. Usia peserta didik SMP berada pada kisaran 13-15 tahun. Pada usia ini masih banyak peserta didik yang berfikir secara konkrit karena masa peralihan, artinya bahwa ketika meraka menerima pelajaran masih membutuhkan media atau perantara untuk memahami materi yang mereka terima.

Menurut Anshory et al., n.d.(2016) masa ini disebut masa remaja di mana tahapan perkembangan ini berlangsung antara usia 13 - 21 tahun , tahapan ini harus dilewati dengan berbagai masalah dan hambatan, masalah dan hambatan tidak saja bagi peserta didik itu sendiri akan tetapi juga masyarakat dan orangorang disekitarnya. Perkembangan pada tahapan ini oleh banyak para ahli disebut dengan masa pancaroba atau labil. Pada masa ini peserta didik sudah memiliki dorongan dan kemampuan mental untuk memahami konsep, logika kebenaran dan simbol-simbol yang mempunyai makna tertentu. Pada umumnya usia anak berada di kisaran 13-15 tahun ini belum mencapai tahap formal. Sehinga banyak peserta didik yang masih berkesulitan memahami materi matematika. Hal ini sesuai dengan pernyataan Fleener et al. (Amelia, 2015) menyatakan bahwa materi matematika di SMP adalah materi yang abstrak sehingga siswa seringkali merasa kesulitan dalam memahami materi-materi di SMP.

Pentingnya media dalam kegiatan pembelajaran bertujuan untuk memudahkan peserta didik dalam menangkap isi materi dan memahami konsep materi matematika tersebut. Hal ini sejalan dengan pendapat Adinugraha, (2018) media pembelajaran berfungsi sebagai sarana untuk pempermudah pembelajaran. Media sebagai bagian yang tidak dapat dipisahkan dari proses belajar mengajar bertujuan untuk memudahkan peserta didik dalam mencapai tujuan pendidikan dan tujuan pembelajaran pada umumnya (Arsyad, 2011).

Dengan konsep guru sebagai fasilitator maka guru meliliki tuntutan besar sebagai sosok yang kreatif dalam mengajarkan materi pelajaran agar materi yang disampaikan dapat membekas dalam ingatan peserta didik dan rasa senang untuk mempelajarinya. Dengan menggunakan dan menerapkan media sebagai salah satu cara menyampaikan materi pembelajaran tentunya diharapkan dapat memancing segala aspek positif peserta didik terhadap matematika. Hal ini sejalan dengan pendapat Nulhakim et al., (2019) yang menyatakan penggunaan media sebagai sarana bantu penyampaian materi dari presenter ke audien dimungkinkan akan menghidupkan suasana daripada presenter hanya sekedar berbicara langsung tanpa media, dengan penggunaan media itu presenter dapat menghidupkan suasana. 
Dengan media pembelajaran diharapkan peserta didik dapat terlibat dalam pembelajaran secara aktif baik fisik, mental, emosional dan aktivitas sosialnya. Disamping menunjukan kegiatan belajar menggunakan media pembelajaran, diharapkan mencapai hasil pembelajaran yang tinggi serta menambah pengalaman belajar bagi peserta didik. Hal ini sejalan dengan pendapat Arsyad, (2011) yang mengemukakan bahwa pemakaian media pembelajaran dalam proses belajar mengajar dapat membangkitkan keinginan dan minat yang baru, membangkitkan motivasi dan rangsangan kegiatan belajar, dan bahkan membawa pengaruhpengaruh psikologis pada siswa.

Berbagai penelitian yang telah dilakukan terhadap penggunaan media pembelajaran dalam proses belajar mengajar sampai pada kesimpulan bahwa proses dan hasil belajar siswa menunjukkan perbedaan yang berarti antara pembelajaran tanpa media dengan pembelajaran menggunakan media. Seperti penelitian yang dilakukan oleh Susiaty \& Oktaviana, (2018) Pemanfaatan media pembelajaran mampu membantu siswa dalam peningkatan pemahaman konsep sebesar $42,969 \%$. Oleh sebab itu penggunaan media pembelajaran dalam proses belajar mengajar sangat dianjurkan untuk mempertinggi kualitas pembelajaran termasuk didalamnya media komputer. Sudjana \& Rivai (Safitri et al., 2013:6). Hal ini juga sejalan dengan yang dikemukakan oleh Syamsiah, (2017) yang menyatakan bahwa komputer dapat digunakan sebagai media dalam proses belajar mengajar yang mempunyai fungsi sebagai media tutorial sehingga akan sangat membantu dalam proses penyampaian dan pemahaman terhadap materi yang disampaikan.

\section{METODE PENELITIAN}

Penelitian ini bertujuan untuk mengetahui bagaimana media pembelajaran mampu memberikan bantuan pemahaman materi kepada peserta didik pada materi PLDV. Penelitian ini melibatkan 10 peserta didik sebagai sampel uji terbatas dan dilaksanakan di salah satu SMP Swasta di Jakarta. Model pengembangan yang digunakan dalam mengembangkan multimedia pembelajaran ini mengusung pada model Borg and Gall (Zuhdan K. Prasetyo, 2012). Instrumen yang digunakan menggunakan Skala Likert. Untuk instrumen uji ahli matematika sebanyak 8 aspek penilaian, Untuk instrumen uji ahli pendidikan sebanyak 14 aspek penilaian dan untuk instrumen uji ahli multimedia terdiri dari 5 aspek penilaian, yaitu SK jika (Sangat Kurang), jawaban K jika (Kurang), jawaban C jika (Cukup), jawaban B jika (Baik), dan jawaban SB jika (Sangat Baik). Untuk instrumen uji terbatas terdiri dari 12 aspek penilaian.

\section{HASIL DAN PEMBAHASAN}

Penelitian ini di fokuskan pada materi PLDV. Produk yang di hasilkan memadukan antara media dengan bahan ajar PLDV. Dalam pembuatan media pembelajaran PLDV digunakan sketsa desain dalam bentuk flowchart dan storyboard. Berikut adalah tampilan media dan hasil pengujian media nya:

\section{Tampilan Materi PLDV}

Bagian ini berisi tampilan, serta pengenalan tentang materi PLDV. Materi ini memperlihatkan berbagai tampilan simulasi baik animasi bagi peserta didik yang akan menggunakan simulasi ini.

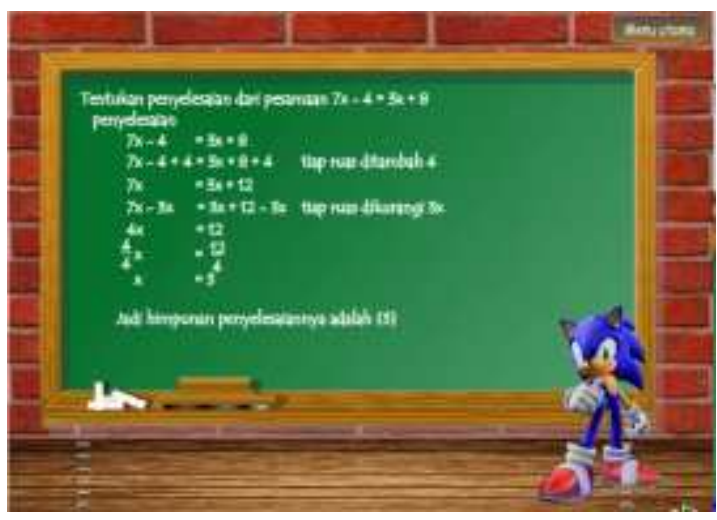

Gambar 1. Tampilan Materi PLDV

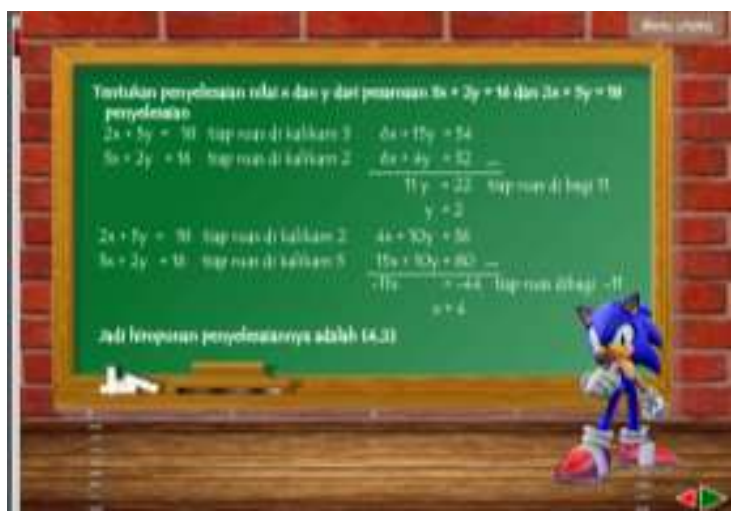

Gambar 2. Tampilan Materi PLDV 


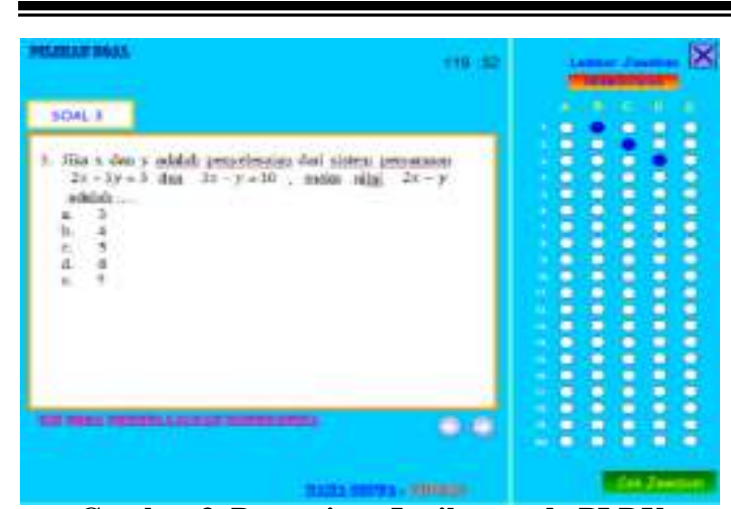

Gambar 3. Pengerjaan Latihan pada PLDV

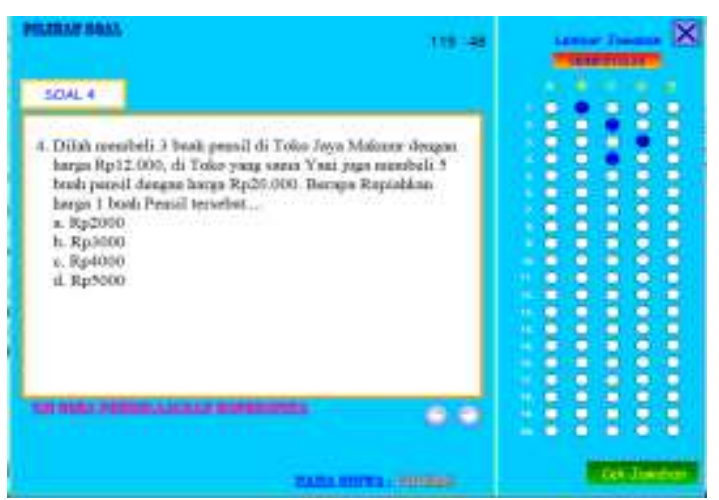

Gambar 4. Pengerjaan Latihan pada PLDV

\section{Uji Pakar}

\section{Ahli Pendidikan}

Ahli pendidikan memberikan penilaian dengan rata-rata sebesar $72,86 \%$ pada kategori baik. (Riduwan, 2010). Berikut adalah tabel hasil uji ahli Pendidikan.

\section{Tabel 1. Hasil Angket 1 Uji Ahli Pendidikan}

\begin{tabular}{|c|c|c|c|c|}
\hline No & Aspek & $\begin{array}{c}\text { Skor } \\
\text { Mentah }\end{array}$ & $\begin{array}{l}\text { Skor } \\
\text { Ideal }\end{array}$ & $\begin{array}{c}\text { Present } \\
(\%)\end{array}$ \\
\hline 1 & $\begin{array}{l}\text { Kelengkapa } \\
\mathrm{n} \text { penyajian } \\
\text { materi } \\
\text { PLDV }\end{array}$ & 4 & 5 & 80 \\
\hline 2 & $\begin{array}{l}\text { Kesesuaian } \\
\text { materi } \\
\text { dengan } \\
\text { SK/KD }\end{array}$ & 4 & 5 & 80 \\
\hline 3 & $\begin{array}{l}\text { Sistematika } \\
\text { penyajian } \\
\text { materi }\end{array}$ & 4 & 5 & 80 \\
\hline 4 & $\begin{array}{l}\text { Merangsan } \\
\text { g } \\
\text { kemampuan } \\
\text { analisis } \\
\text { peserta } \\
\text { didik }\end{array}$ & 3 & 5 & 60 \\
\hline 5 & $\begin{array}{l}\text { Ejaan } \\
\text { sesuai } \\
\text { dengan } \\
\text { kaidah } \\
\text { bahasa } \\
\text { indonesia }\end{array}$ & 4 & 5 & 80 \\
\hline
\end{tabular}

\begin{tabular}{|c|c|c|c|c|}
\hline 6 & $\begin{array}{l}\text { Keruntutan } \\
\text { materi } \\
\text { penyelesaia } \\
\mathrm{n}\end{array}$ & 4 & 5 & 80 \\
\hline 7 & $\begin{array}{l}\text { Penempatan } \\
\text { unsur tata } \\
\text { letak } \\
\text { konsisten }\end{array}$ & 3 & 5 & 60 \\
\hline 8 & $\begin{array}{l}\text { Menumbuh } \\
\text { kan berpikir } \\
\text { kritis, } \\
\text { analitis }\end{array}$ & 3 & 5 & 60 \\
\hline 9 & $\begin{array}{l}\text { Kelengkapa } \\
\text { n materi }\end{array}$ & 4 & 5 & 80 \\
\hline 10 & $\begin{array}{l}\text { Keluasan } \\
\text { materi }\end{array}$ & 4 & 5 & 80 \\
\hline 11 & $\begin{array}{l}\text { Ketertautan } \\
\text { antarbab/su } \\
\text { bbab/alinea }\end{array}$ & 4 & 5 & 80 \\
\hline 12 & $\begin{array}{l}\text { Mendorong } \\
\text { keinginan } \\
\text { peserta } \\
\text { didik untuk } \\
\text { memahami } \\
\text { materi lebih } \\
\text { mendalam }\end{array}$ & 3 & 5 & 60 \\
\hline 13 & $\begin{array}{l}\text { Memberika } \\
\mathrm{n} \text { tantangan } \\
\text { bagi peserta } \\
\text { didik }\end{array}$ & 3 & 5 & 60 \\
\hline 14 & $\begin{array}{l}\text { Keakuratan } \\
\text { contoh, } \\
\text { tugas, dan } \\
\text { latihan soal }\end{array}$ & 4 & 5 & 80 \\
\hline & Total & 51 & 70 & 72.86 \\
\hline
\end{tabular}

\section{Ahli Multimedia}

Ahli multimedia memberikan penilaian dengan rata-rata sebesar $72 \%$ pada kategori baik. (Riduwan, 2010). Berikut adalah tabel hasil uji ahli multimedia.

Tabel 2. Hasil Uji Ahli Multimedia

\begin{tabular}{clccc}
\hline No. & \multicolumn{1}{c}{ Aspek } & $\begin{array}{c}\text { Skor } \\
\text { Mentah }\end{array}$ & $\begin{array}{c}\text { Skor } \\
\text { Ideal }\end{array}$ & $\begin{array}{c}\text { Present } \\
(\mathbf{\%})\end{array}$ \\
\hline $\mathbf{1}$ & $\begin{array}{l}\text { Arsitektur } \\
\text { tampilan }\end{array}$ & 3 & 5 & 60 \\
\hline $\mathbf{2}$ & $\begin{array}{l}\text { Integritas } \\
\text { warna }\end{array}$ & 4 & 5 & 80 \\
\hline $\mathbf{3}$ & $\begin{array}{l}\text { Desain } \\
\text { background }\end{array}$ & 4 & 5 & 80 \\
\hline $\mathbf{4}$ & $\begin{array}{l}\text { Animasi } \\
\text { dan ilustrasi }\end{array}$ & 4 & 5 & 80 \\
\hline $\mathbf{5}$ & $\begin{array}{l}\text { Struktur } \\
\text { penempaan } \\
\text { file }\end{array}$ & 3 & 5 & 60 \\
\hline & Total & $\mathbf{1 8}$ & $\mathbf{2 5}$ & 72 \\
\hline
\end{tabular}


3. Ahli Matematika

Ahli matematika memberikan penilaian dengan rata-rata sebesar $75 \%$ pada kategori baik. (Riduwan, 2010). Berikut adalah tabel hasil uji ahli matematika.

Tabel 3. Hasil Uji Ahli Matematika

\begin{tabular}{ccccc}
\hline No & \multicolumn{1}{c}{ Aspek } & $\begin{array}{c}\text { Skor } \\
\text { Mentah }\end{array}$ & $\begin{array}{c}\text { Skor } \\
\text { Ideal }\end{array}$ & $\begin{array}{c}\text { Present } \\
(\%)\end{array}$ \\
\hline $\mathbf{1}$ & $\begin{array}{l}\text { Kesesuaian } \\
\text { contoh } \\
\text { materi } \\
\text { pembelajaran } \\
\text { matematika }\end{array}$ & 3 & 5 & 60 \\
\hline $\mathbf{2}$ & $\begin{array}{l}\text { Keakuratan } \\
\text { fakta dan } \\
\text { data }\end{array}$ & 4 & 5 & 80 \\
\hline $\mathbf{3}$ & $\begin{array}{l}\text { Pemecahan } \\
\text { masalah }\end{array}$ & 4 & 5 & 80 \\
\hline
\end{tabular}

\begin{tabular}{|c|c|c|c|c|}
\hline 4 & $\begin{array}{l}\text { Keakuratan } \\
\text { gambar pada } \\
\text { materi }\end{array}$ & 4 & 5 & 80 \\
\hline 5 & $\begin{array}{l}\text { Keakuratan } \\
\text { simbol, dan } \\
\text { ikon } \\
\text { matematika }\end{array}$ & 4 & 5 & 80 \\
\hline 6 & $\begin{array}{l}\text { Keakuratan } \\
\text { konsep dan } \\
\text { penyelesaian } \\
\text { masalah } \\
\text { PLDV }\end{array}$ & 4 & 5 & 80 \\
\hline 7 & $\begin{array}{l}\text { Kesesuaian } \\
\text { dengan } \\
\text { karakteristik } \\
\text { mata } \\
\text { pelajaran }\end{array}$ & 4 & 5 & 80 \\
\hline 8 & $\begin{array}{l}\text { Kemenarikan } \\
\text { materi }\end{array}$ & 3 & 5 & 60 \\
\hline & Total & 30 & 40 & 75 \\
\hline
\end{tabular}

\section{Uji Terbatas}

Setelah dilakukannya seluruh proses uji ahli dan revisi produk bahan ajar pada desain awal, maka dilanjutkan dengan uji coba produk secara terbatas terhadap 10 peserta didik di SMP. Berikut adalah tabel hasil uji terbatas.

Tabel 4. Hasil Angket Uji Terbatas

\begin{tabular}{|c|c|c|c|c|c|c|c|}
\hline \multirow{2}{*}{ No } & \multirow{2}{*}{ Daftar Pertanyaan } & \multicolumn{5}{|c|}{ Jawaban } & \multirow{2}{*}{$\begin{array}{c}\text { Persentase } \\
(\%)\end{array}$} \\
\hline & & SS & $\mathbf{S}$ & RG & TS & STS & \\
\hline 1 & $\begin{array}{l}\text { Saya senang belajar matematika menggunakan media } \\
\text { pembelajaran karena contoh yang di sajiakan mudah } \\
\text { dipahami }\end{array}$ & 5 & 3 & 2 & 0 & 0 & 86 \\
\hline 2 & $\begin{array}{l}\text { Bahan ajar ini membuat saya lebih mandiri untuk } \\
\text { memahami meski tanpa bantuan Bapak/Ibu Guru }\end{array}$ & 2 & 4 & 4 & 0 & 0 & 76 \\
\hline 3 & $\begin{array}{l}\text { Media pembelajaran ini dapat saya pelajari di sekolah } \\
\text { maupun di rumah }\end{array}$ & 4 & 4 & 2 & 0 & 0 & 84 \\
\hline 4 & $\begin{array}{l}\text { Saya terbiasa memeriksa kembali hasil pekerjaan saya } \\
\text { dari awal sebelum di serahkan ke Bapak/Ibu Guru }\end{array}$ & 4 & 5 & 1 & 0 & 0 & 86 \\
\hline 5 & $\begin{array}{l}\text { Jika terdapat kesulitan dalam menyelesaikan masalah } \\
\text { matematika biasanya saya selalu berdiskusi untuk } \\
\text { memecahkan masalah tersebut dan mencari sumber } \\
\text { alternatif untuk menyelesaikannya daripada mencontek } \\
\text { pekerjaan peserta didik lain }\end{array}$ & 1 & 7 & 2 & 0 & 0 & 78 \\
\hline 6 & $\begin{array}{l}\text { Saya selalu merasa optimis dalam mengerjakan latihan } \\
\text { soal yang diberikan Bapak/Ibu }\end{array}$ & 2 & 7 & 1 & 0 & 0 & 82 \\
\hline 7 & $\begin{array}{l}\text { Simulasi dan contoh materi yang digunakan pada } \\
\text { media pembelajarann ini mudah pahami }\end{array}$ & 3 & 7 & 0 & 0 & 0 & 86 \\
\hline 8 & $\begin{array}{l}\text { Simulasi latihan soal yang sajika dalam media } \\
\text { pembelajaran ini memiliki } \\
\text { diselesaikan }\end{array}$ & 2 & 4 & 4 & 0 & 0 & 76 \\
\hline 9 & $\begin{array}{l}\text { Media pembelajaran ini membuat saya mengerti } \\
\text { matematika ternyata berguna untuk menyelesaikan } \\
\text { persoalan kehidupan sehari-hari }\end{array}$ & 3 & 5 & 2 & 0 & 0 & 82 \\
\hline 10 & $\begin{array}{l}\text { Bahan ajar ini membuka wawasan saya bertambah dan } \\
\text { memunculkan rasa optimis belajar terhadap materi } \\
\text { yang disajikan }\end{array}$ & 3 & 6 & 1 & 0 & 0 & 84 \\
\hline 11 & $\begin{array}{l}\text { Saya lebih memahami materi pembelajaran PLDV } \\
\text { menggunakan buku ajar dan penjelasan dari guru dari } \\
\text { pada dengan media pembelajaran ini. }\end{array}$ & 0 & 1 & 3 & 5 & 1 & 72 \\
\hline
\end{tabular}




\section{PEMBAHASAN}

\section{Mengembangkan Bahan Ajar Interaktif PLDV}

Bahan ajar sebagai salah satu media pembelajaran dapat diterapkan dan dimanfaatkan oleh guru maupun peserta didik pada saat praktik pembelajaran langsung di dalam maupun di luar kelas. Mengembangkan media interaktif pada materi PLDV dimanfaatkan untuk meningkatkan kemandirian belajar matematika peserta didik SMP.

Media pembelajaran yang dikembangkan berorientasi pada solusi penyelesaian materi ajar yang berisi informasi dan cara penyelesaian masalah pada pemodelan matematika.

Manfaat pengembangan bahan ajar bagi peserta didik, antara lain:

1. menjadikan kegiatan pembelajaran menjadi lebih menarik,

2. memberikan kesempatan untuk belajar secara mandiri dan mengurangi ketergantungan terhadap kehadiran guru di kelas, dan

3. memberikan kemudahan dalam mempelajari kompetensi yang harus dikuasai. (Susiaty \& Oktaviana, 2018)

\section{Merancang Bahan Ajar Interaktif Berbasis Aktivitas Belajar Peserta Didik.}

Masih banyaknya guru yang merasa nyaman dengan pembelajaran klasikal membuat guru belum mampu beranjak dan bergeser untuk membangun dan menyelenggarakan pembelajaran menarik dan menyenangkan melibatkan sumber dan media terbaru. Keadaan ini salah satunya tidak terlepas jarang adanya sosilaisasi untuk menciptakan media pembelajaran kepada guru-guru agar terus mengupdate pengetahuan dan pengalaman membangun bahan ajar yang inovatif.

Selama ini guru cenderung nyaman menggunakan konsep pembelajaran klasikal karena dirasa paling simple dan mudah untuk dilaksanakan. Tetapi dari sisi lain peserta didik hanya menjadi pendengar setia karena aktivitas pemberian materi berlangsung hanya mengangkat unsur visual dan audio peserta didik dengan kurang mengaktifkan aktivitasnya. Oleh karena itu, diperlukan suatu cara belajar baru yang dapat melibatkan seluruh indra peserta didik agar mampu memaksimalkan proses pembelajaran.

\section{Kemandirian Belajar}

Dalam proses kemandirian belajar peserta didik diharapkan mampu memahami materi PLDV dengan mempelajari bahan ajar secara mandiri seraya di bantu oleh guru nya sebagai Fasilitator. Pengembangan media pembelajaran diarahkan kepada sudut pandang peserta didik agar mampu terlibat secara emosional karena media dikembangkan kepada cara belajar peserta didik agar peserta didik bisa belajar secara mandiri. Media belajar ini bersifat menuntun peserta didik untuk pembaca dan memahami isi materi secara mandiri.

\section{SIMPULAN DAN SARAN}

Setelah dilakukan berbagai tahap pengembangan pada produk bahan ajar belajar ini, pengembang menyimpulkan bahwa mengembangkan bahan ajar PLDV harus mampu membuat seluruh indra peserta didik terbawa dalam suasana belajar yang menyenangkan. Tantangan utama membuat media ini adalah merangsang agar peserta didik tidak bosan dengan media tersebut. Proses pengujian bahan ajar dilakukan oleh beberapa ahli serta uji coba terbatas juga dilakukan kepada 10 peserta didik yang berperan sebagai sasaran utama dari pengembangan bahan ajar ini.

Proses uji ahli dilakukan kepada ahli pendidikan, matematika dan multimedia, dan setelah proses uji ahli, pengembang melakukan revisi dan dilanjutkan dengan proses pengujian skala terbatas terhadap 10 peserta didik. Berikut adalah ringkasan hasil uji ahli dan uji terbatas nya:

Skor akhir dari masing-masing pengujian yaitu :

1. Uji ahli pendidikan sebesar $72,86 \%$. 
2. Uji ahli multimedia skor akhir $72 \%$.

3. Uji ahli matematika skor akhir $75 \%$.

4. Uji skala terbatas skor akhir $81 \%$.

Berdasarkan keseluruhan skor yang telah diperoleh dari proses pengujian tersebut menunjukan bahwa bahan ajar ini layak digunakan.

Berdasarkan hasil pengujian yang dilakukan, ada beberapa saran yang dapat peneliti sampaikan:

1. Media ini dapat dijadikan acuan untuk penelitian berikutnya terutama perlunya menambahkan unsur persamaan garis dalam menyatakan persamaan linear nya.

2. Diharapkan ada pengujian lanjutan dengan skala yang lebih luas.

3. Bahan ajar dapat digunakan sumber belajar bagi peserta didik, reverensi bagi guru, dan sebagai alternatif model pembelajaran di sekolah selain pembelajaran klasikal.

\section{DAFTAR PUSTAKA}

Abdullah, \& Suratno, J. (2015). Terhadap Kemampuan Komunikasi Matematis Siswa. Jurnal Pengajaran MIPA, 20(2), 112-115.

Adinugraha, F. (2018). Model Pembelajaran Berbasis Proyek pada Mata Kuliah Media Pembelajaran. 3(1), 1-9.

Amelia, S. (2015). Pengaruh Accelerated Learning Cycle Terhadap Kemampuan Pemecahan Masalah Matematis Siswa SMP. Jurnal Pengajaran Matematika Dan Ilmu Pengetahuan Alam, 6(1), 122. https://doi.org/10.18269/jpmipa.v20i2.5 74

Anshory, I., Yayuk, E., \& Dyah, W. E. (n.d.). Tahapan dan Karakteristik Perkembangan Belajar Siswa Sekolah Dasar (Upaya Pemaknaan Development Task). Retrieved November 20, 2021, from https://eprints.umm.ac.id/42236/

Arsyad, A. (2011). Media Pembelajaran. Rajawali Prees. https://ebook.sultrakini.com/ms/azhararsyad-2011-media-pembelajaranpdf.pdf

Nulhakim, A. L., Susanto, A., Nugraha, M. L., \& Nengsih, R. (2019). Trik Menggunakan Adobe Flash Dalam Media Pembelajaran Interaktif (Ghofar
El Ghifari (ed.)). El Nisa Media Utama. Pardjono. (2000). Konsepsi Guru Tentang Belajar dan Mengajar dalam Persfektif Belajar Aktif. Jurnal Psikologi, 23(2), 73-83.

Riduwan, D. (2010). Pengantar Statistika untuk Penelitian Pendidikan, Sosial, Ekonomi, Komunikasi dan Bisnis. Alfabeta.

Safitri, M., Hartono, Y., \& Somakim. (2013). Pengembangan media pembelajaran matematika pokok bahasan segitiga menggunakan. Sentra Penelitian Engineering Dan Edukasi, 5 No 2(2), 28-35.

Susiaty, U. D., \& Oktaviana, D. (2018). Desain Aplikasi Media Pembelajaran untuk Membantu Pemahaman Siswa Tentang Konsep Geometri. 3(1), 18-26.

Syamsiah. (2017). Pengembangan Aplikasi Multimedia Pembelajaran Interaktif untuk Mata Pelajaran Bahasa Indonesia. 2(1), 53-63.

Zuhdan K. Prasetyo. (2012). Research and Development Pengembangan Berbasis Penelitian. Universitas Negeri Sebelas Maret. http://staff.uny.ac.id/sites/default/files/p engabdian/zuhdan-kun-prasetyo-meddr-prof/research-and-developmentpengembangan-berbasis-penelitian.pdf 